\title{
Fulminant myocarditis managed with pulsatile extracorporeal life support; use of Twin Pulse Life support $\left(\mathrm{T}-\mathrm{PLS} \mathrm{S}^{\circledR}\right)$
}

\author{
Eun Jeung Cho ${ }^{1}$, Joonhwa Hong ${ }^{2 *}$, Hyun $\mathrm{Kang}^{3}$, Ju Won Choe ${ }^{2}$ and Sang-Wook Kim ${ }^{1}$
}

\begin{abstract}
Fulminant myocarditis frequently results in severe hemodynamic deterioration. High-dose vasopressors or sometimes mechanical circulatory support are required. We report on two cases of fulminant myocarditis successfully treated with pulsatile extracorporeal life support (T-PLS ${ }^{\circledR}$, Twin Pulse Life support, New heart bio.BHK, Seoul, Korea). With T-PLS, we were able to provide mechanical support to patients until they recovered completely.
\end{abstract}

Keywords: myocarditis, extracorporeal circulation

\section{Introduction}

We report on two cases of fulminant myocarditis. They developed profound hypoxemia, acidosis, pulmonary edema, and oliguria. T-PLS ${ }^{\mathbb{B}}$ (Twin Pulse Life support, New heart bio.BHK, Seoul, Korea) was used in order to prevent further deterioration. Both patients recovered well from fulminant myocarditis with T-PLS support. Echocardiograms showed normal ejection fraction after recovery. Written informed consent was obtained from the patient for publication of this case report and accompanying images. A copy of the written consent is available for review by the Editor-in-Chief of this journal.

\section{Case 1}

A 32-year-old woman without previous medical history was referred to the emergency department with dizziness for one day. On admission, the vital signs were unstable, with a blood pressure of $70 / 40 \mathrm{mmHg}$, heart rate of 91 beats $/ \mathrm{min}$, and body temperature of $35.4^{\circ} \mathrm{C}$. White blood cell count was $16,47010^{9} / \mathrm{L}$ and troponin I was $2.563 \mathrm{ng} / \mathrm{mL}$. Arterial blood gas analysis showed metabolic acidosis. EKG demonstrated sinus tachycardia. Hemodynamic status showed rapid deterioration during the subsequent hours. Systolic blood pressure was below

\footnotetext{
* Correspondence: joonhwa.hong@gmail.com

${ }^{2}$ Department of Thoracic and Cardiovascular Surgery, Chung-Ang University

Hospital, Heukseok-dong, Dongjak-gu, Seoul, Korea 156-755 Full list of author information is available at the end of the article
}

$90 \mathrm{mmHg}$, with a heart rate faster than 100 beats/min. Urine output decreased, too. Hypoxemia did not resolve with supplementary oxygen. Echocardiogram showed a left ventricular ejection fraction of $21 \%$ with global hypokinesia. She was admitted to the intensive care unit (ICU) with a diagnosis of probable viral myocarditis. Ventilator therapy was initiated. She developed atrial fibrillation with rapid ventricular response. Hemodynamic status showed further worsening. Urine output further decreased and she developed hypoxemia with pulmonary edema, lactic acidosis. On the second day of admission, we decided to place the patient on a T-PLS. A 17 French femoral venous and a 14 French arterial cannula were inserted percutaneously. The pump was started with a flow of $2.13 \mathrm{~L} / \mathrm{min} / \mathrm{m}^{2}$, a pump rate of $47 / \mathrm{min}$, and $100 \%$ oxygen at $4 \mathrm{~L} / \mathrm{min}$. The membrane oxygenator was replaced as required when oxygenation is not adequate $\left(\mathrm{PaO}_{2}<100\right.$ with $\mathrm{FiO}_{2}$ of 1.0) due to plasma leakage. Serial chest X-rays showed improving pulmonary edema after T-PLS insertion (Figure 1). On day 10, T-PLS was weaned down slowly and removed. Changes of inotropic agent and pump flow rate are shown in Table 1. Blood serology showed elevated titers of Coxsackievirus B4(1:64), Coxsackievirus B2(1:16), Coxsackievirus B3.5(1:8), and Adenovirus IgM. Six days after removal of T-PLS, echocardiography showed improved cardiac function (LVEF of 68\%) with minimal pericardial effusion. The patient was discharged on the
C Biomed Central 


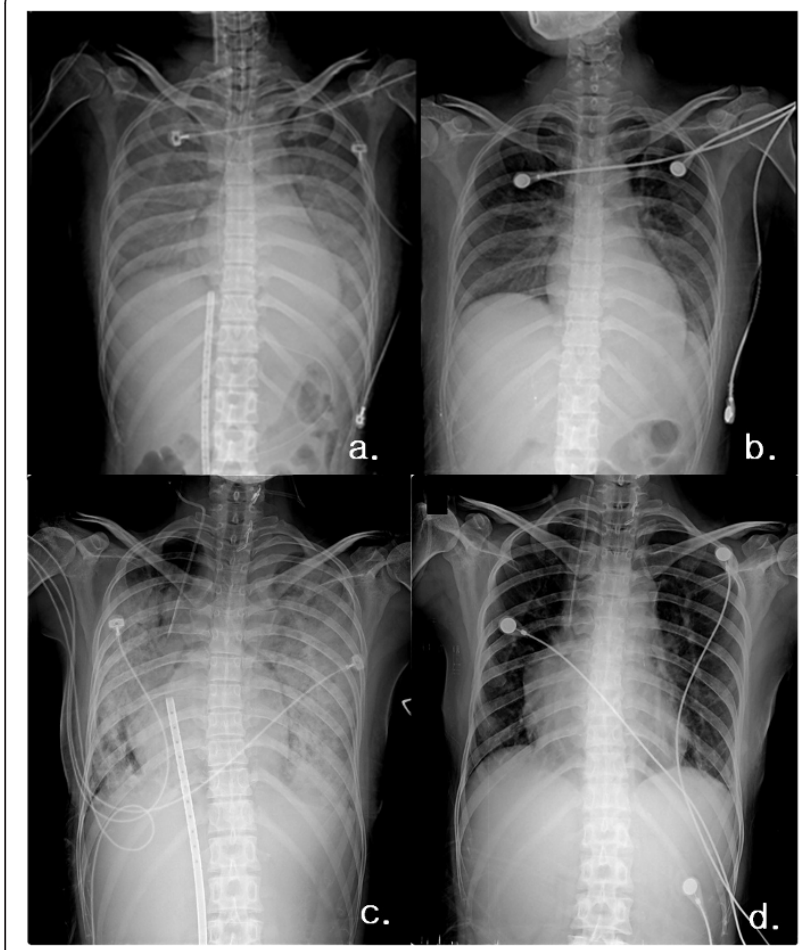

Figure 1 Chest $\mathbf{x}$-ray comparison of both cases. a. Case $1,3^{\text {rd }}$ day of T-PLS. b. Case $1,10^{\text {th }}$ day of T-PLS, day of weaning. c. Case 2 , $2^{\text {nd }}$ day of T-PLS. d. Case $2,13^{\text {th }}$ day of T-PLS, one day after weaning.

25th hospital day. Six months later, echocardiography was normal, with LVEF of $64 \%$.

\section{Case 2}

A 36-year-old women with a history of cardiac surgery for treatment of Tetralogy of fallot 35 years ago and dextrocardia presented to the emergency department with fever and dyspnea for 2 days. On admission, blood pressure was $70 / 50 \mathrm{mmHg}$, pulse rate was 120 beats/ min, and body temperature was $36.5^{\circ} \mathrm{C}$. White blood cell count was $16,47010^{9} / \mathrm{L}$. EKG demonstrated sinus tachycardia and chest radiography showed pulmonary edema. Troponin I was elevated to $13.72 \mathrm{ng} / \mathrm{mL}$. Echocardiogram showed depressed global left ventricular ejection fraction(28\%). The patient was admitted to the intensive care unit. Nine hours after admission, troponin I increased to $42.459 \mathrm{ng} / \mathrm{mL}$. She developed hypoxemia and hemodynamic status showed rapid deterioration with acidosis, oliguria during the subsequent hours, despite a high dose of inotropics and vasopressors. The patient was intubated and T-PLS was initiated with a percutaneous 17 French femoral venous and a 14 French arterial cannula. The pump started with a flow of $1.69 \mathrm{~L} / \mathrm{min} / \mathrm{m}^{2}$, a pump rate of $70 / \mathrm{min}$, and $100 \%$ oxygen flow at $5 \mathrm{~L} /$ minute. Arterial blood from the right radial artery was $100 \%$ after T-PLS insertion and the patient could be extubated. The membrane oxygenator was replaced on the $3 \mathrm{rd}, 6^{\text {th }}$, and $9^{\text {th }}$ days when oxygenation was not adequate. On day 12 , blood pressure was $100 / 60 \mathrm{mmHg}$, and pulse rate was 80 beats/min, with a T-PLS flow of $1.75 \mathrm{~L} / \mathrm{min} / \mathrm{m}^{2}$. White blood cell count decreased to $9,24010^{9} / \mathrm{L}$, and troponin I decreased to $0.130 \mathrm{ng} / \mathrm{ml}$. Arterial blood gas analysis was satisfactory. Left ventricular systolic function (LVEF $52 \%$ ) and chest $\mathrm{x}$-ray (Figure 1) were much improved. T-PLS was weaned slowly down to off and removed successfully as shown in Table 1. Blood serology showed elevated titers of Coxsackie virus B4 (1:64) and Coxsackie virus B3 (1:32). Forty two days after TPLS, echocardiography showed normal systolic function (LVEF 57\%) with mild pericardial effusion. Twelve months later, echocardiography showed normal cardiac function (LVEF 60\%).

\section{Discussion}

Fulminant myocarditis is an inflammation of the myocardium, which is caused by viral, bacterial, or protozoal infections, drug toxicity, or immunological reaction [1]. Fulminant myocarditis is characterized by acute onset with severe hemodynamic deterioration. Diagnosis of fulminant myocarditis in the early stages of the disease may be difficult. It may be initially misdiagnosed as septic shock, in which myocardial dysfunction and mild troponin I elevation are commonly seen [1,2]. Fulminant myocarditis is different from acute myocarditis in its clinical features $[1,3]$. Fulminant myocarditis was diagnosed on the basis of clinical features at presentation, including the presence of severe hemodynamic

Table 1 Inotropics support and T-PLS setting for the initial and weaning period

\begin{tabular}{|c|c|c|c|c|c|c|c|}
\hline & & \multicolumn{3}{|c|}{ Inotropics } & \multicolumn{3}{|c|}{ T-PLS settings } \\
\hline & & $\begin{array}{l}\text { Norepi } \\
(\mu \mathrm{g} / \mathrm{min})\end{array}$ & $\begin{array}{c}\text { Dopa } \\
(\mu \mathrm{g} / \mathrm{kg} / \mathrm{min})\end{array}$ & $\begin{array}{c}\text { Dobuta } \\
(\mu \mathrm{g} / \mathrm{kg} / \mathrm{min})\end{array}$ & $\begin{array}{l}\text { Flow } \\
(\mathrm{L} / \mathrm{min})\end{array}$ & $\begin{array}{l}\text { Pump rate } \\
\text { (rate/min) }\end{array}$ & $\begin{array}{l}\text { Oxygen } \\
\text { (L/min) }\end{array}$ \\
\hline \multirow[t]{2}{*}{ Case 1} & Initial & 30 & 50 & 15 & 2.13 & 47 & 4 \\
\hline & Weaning & 0 & 4 & 5 & 1.07 & 33 & 2 \\
\hline \multirow[t]{2}{*}{ Case 2} & Initial & 30 & 40 & 30 & 1.69 & 70 & 5 \\
\hline & Weaning & 0 & 15 & 6 & 1.07 & 33 & 1.5 \\
\hline
\end{tabular}

Norepi, Norepinephrine; Dopa, Dopamine; Dobuta, Dobutamine 


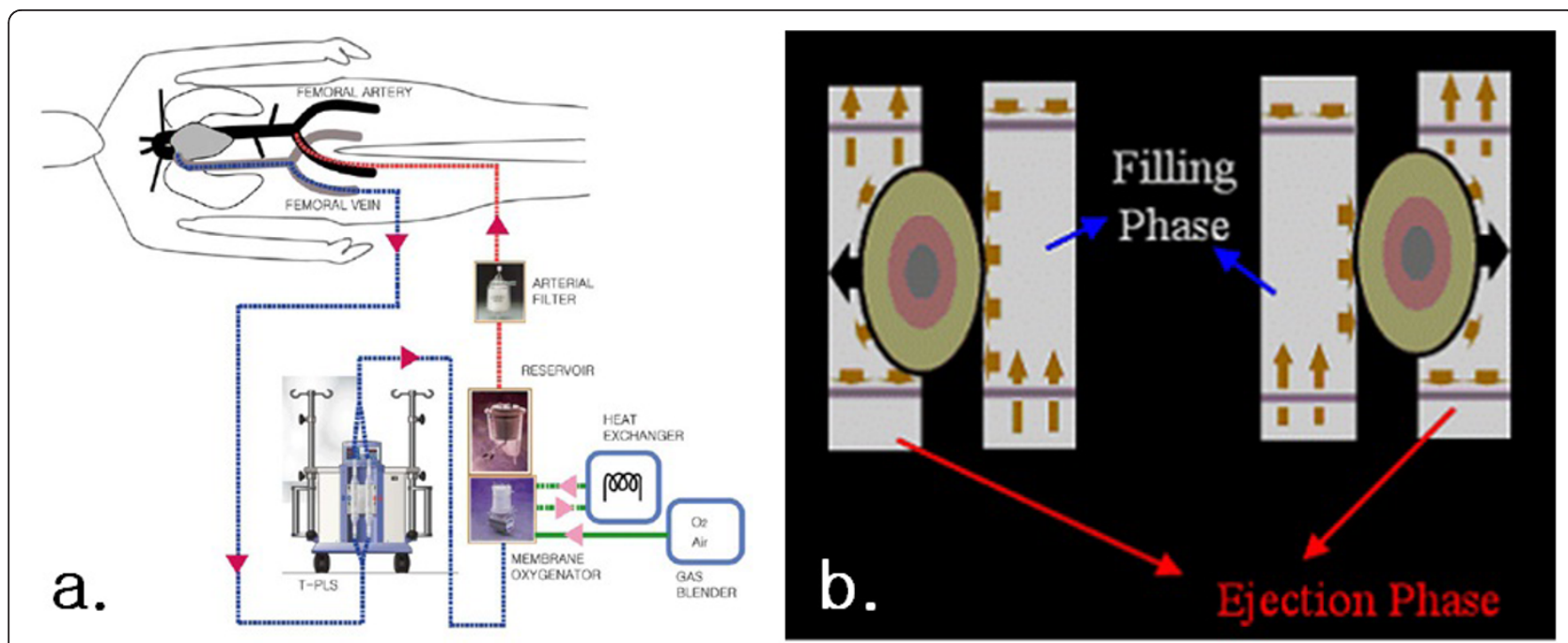

Figure 2 Schematic diagram of T-PLS. a. Connection to patient. b. Action mechanism; the reciprocating actuator pushes on blood sacs alternatively, causing pulsatile flow

compromise, rapid onset of symptoms, and fever. On the other hand, acute myocarditis usually shows less severe hemodynamic compromise and did not have these features $[3,4]$.

There is no specific treatment for fulminant myocarditis. Thus, treatment remains supportive. Physicians suspecting fulminant myocarditis must be prepared to use therapeutic options, such as mechanical circulatory support, prior to occurrence of severe organ failure $[1,5,6]$. With appropriate treatment, fulminant myocarditis is commonly reversible within a few days and is associated with better long-term prognosis than acute myocarditis [3].

Mechanical circulatory support in myocarditis is used for maintenance of cardiac output and organ perfusion, and to minimize the need for inotropic support until myocardial recovery. There are several methods for mechanical circulatory support. These include the intraaortic balloon pump, non-pulsatile extracorporeal life support, and pulsatile extracorporeal life support, such as T-PLS, which we used for our cases, and ventricular assist devices.

A non-pulsatile pump has advantages over a pulsatile pump in that it maintains regular blood pressure with less hemolysis during total extracorporeal circulation. However, it does not maintain higher pulse pressure or mean blood pressure than the pulsatile pump [7-9], which probably results in less tissue perfusion [10].

T-PLS has an actuator and two blood sacs, and the reciprocating actuator pushes on the blood sacs alternatively, causing pulsatile flow (Figure 2). The T-PLS system has an effective pulsatility in hemodynamic energy and provides a beneficial effect on the coronary arteries in terms of blood flow, flow velocity, and resistance, and also provides better tissue perfusion than the non-pulsatile pump $[10,11]$. Compared to other pulsatile pumps with different pulse generating mechanisms, the dual sac structure of T-PLS can effectively reduce high membrane oxygenator inlet pressure, and, thus, reduce hemolysis $[7,8,12,13]$.

T-PLS is not synchronized with native heart beat. When it is used in severe heart failure patient where there is very low pulsatility from the heart, no synchronization is required. When the heart is recovered and makes higher pulsatility, T-PLS rate is weaned down so that it does not eject too strongly when the heart ejects.

As proven by previous studies, T-PLS can improve coronary and other tissue perfusion with less hemolysis $[7,8,12]$, and those advantages are essential for treatment of fulminant myocarditis; therefore, we think that T-PLS is one of the most suitable treatment options for fulminant myocarditis.

\section{Author details}

'Division of Cardiology, Chung-Ang University Hospital, Heukseok-dong, Dongjak-gu, Seoul, Korea 156-755. ${ }^{2}$ Department of Thoracic and

Cardiovascular Surgery, Chung-Ang University Hospital, Heukseok-dong, Dongjak-gu, Seoul, Korea 156-755. ${ }^{3}$ Department of anesthesiology and pain medicine, Chung-Ang University Hospital, Heukseok-dong, Dongjak-gu, Seoul, Korea 156-755.

\section{Authors' contributions}

$\mathrm{EC}, \mathrm{JH}$ and SK participated in the sequence alignment and drafted the manuscript. JC participated in taking care of the patients. HK participated in the image preparation and the patients' medical record review. All authors read and approved the final manuscript.

\section{Competing interests}

The authors declare that they have no competing interests. 


\section{References}

1. Burian J, Buser P, Eriksson U: Myocarditis; the immunologist's view on pathogenesis and treatment. Swiss med wkly 2005, 135:359-364.

2. Montcriol A, Wiramus S, Ribeiri A, et al: Successful management of influenza $\mathrm{A}$ associated fulminant myocarditis; mobile circulatory support in intensive care unit; a case report. Case J 2008, 1:46.

3. Felker GM, Boehmer JP, Hruban RH, et al: Echocardiographic Findings in Fulminant and Acute Myocarditis. J Am Coll Cardiol 2003, 36:227-232.

4. Geluk CA, Otterspoor IC, Boeck B, et al: Magnetic resonance imaging in acute myocarditis; a case report and a review of literature. The Netherlands journal of Med 2002, 60(5):223-227.

5. Sasaki H, Kawai A, Kuosawa H: Mechanical Support for Patients with Fulminant Acute Myocarditis: Strategy for Biventricular Failure and Respiratory Failure. J Card Surg 2008, 23:526-527.

6. Shin JS, Lee SW, Han GS, et al: Successful extracorporeal life support in cardiac arrest with recurrent ventricular fibrillation unresponsive to standard cardiopulmonary resuscitation. Resuscitation 2007, 73:309-313.

7. Lee $H S$, Rho YR, Lee HS, et al: In vivo evaluation of the pulsatile ECLS system. J Artif Organs 2003, 6(1):25-29.

8. Rho YR, Choi H, Lee JC, et al: Applications of the pulsatile flow versatile ECLS; in vivo studies. Int J Artif Organs 2003, 26:428-435.

9. Lee $D H$, Jung $T E$, Lee JH: Extracorporeal Life Support with a twin-pulse Life Support (T-PLS) System. Korean I Thorac cardiovasc Surg 2007, 40:512-516.

10. Lee HS, Rho YR, Lee HS: In vivo evaluation of the pulsatile ECLS system. J Artif Organs 2003, 6:25-29.

11. Kim HK, Son HS, Fanc YH, et al: The Effects of Pulsatile Flow Upon Renal Tissue Perfusion During Cardiopulmonary Bypass: A Comparative Study of Pulsatile and Nonpulsatile Flow. ASAIO J 2005, 51:30-36.

12. Lee JJ, Lim CH, Son HS, et al: In vitro evaluation of the performance of korean pulsatile ECLS(T-PLS) Using precise Quantification of pressureFlow Waveforms. ASAIO J 2005, 51:604-608.

13. $\operatorname{Lim} \mathrm{CH}$, Son $\mathrm{HS}$, Lee JJ, et al: Optimization of the circuit configuration of a pulsatile ECLS, An In Vivo Experimental study. ASAIO J 2005, 51:609-613.

doi:10.1186/1749-8090-6-159

Cite this article as: Cho et al:: Fulminant myocarditis managed with pulsatile extracorporeal life support; use of Twin Pulse Life support (TPLS $^{\circledR \oplus}$ ). Journal of Cardiothoracic Surgery 2011 6:159.

\section{Submit your next manuscript to BioMed Central and take full advantage of:}

- Convenient online submission

- Thorough peer review

- No space constraints or color figure charges

- Immediate publication on acceptance

- Inclusion in PubMed, CAS, Scopus and Google Scholar

- Research which is freely available for redistribution

Submit your manuscript at www.biomedcentral.com/submit
CioMed Central 